\title{
A LEGITIMIDADE PARA PROPOSITURA DA AÇÃO PENAL PRIVADA SUBSIDIÁRIA DA PÚBLICA EM CRIMES QUE AFETAM BENS JURÍDICOS COLETIVOS. O EXEMPLO REPRESENTATIVO DOS CRIMES AMBIENTAIS.
}

\author{
Alessandra Rapacci Mascarenhas Prado ${ }^{1}$ \\ Juliana Pinheiro Damasceno e Santos ${ }^{2}$
}

\section{Resumo}

Objetiva-se discutir sobre a legitimidade para propositura da ação privada subsidiária da pública em crimes que afetam interesses coletivos, a exemplo dos crimes ambientais. Parte-se da hipótese de que a garantia processual fundamental deve estar a serviço da tutela penal determinada pelo princípio da exclusiva proteção de bem jurídico. Utiliza-se como metodologia a revisão bibliográfica e a análise da legislação e de julgados do Supremo Tribunal Federal. Conclui-se que é imperativo adotar interpretação que favoreça o acesso à justiça a partir da ampliação do rol de legitimados, para que se possa assegurar a proteção do bem.

Palavras-chave: legitimidade, ação penal, bem jurídico, crime ambiental, queixa crime

\section{STANDING FOR A PRIVATE PERSON TO BRING A CRIMINAL ACTION IN CRIMES AGAINST THE COLLECTIVE INTEREST. THE REPRESENTATIVE EXAMPLE OF ENVIRONMENTAL CRIMES.}

\begin{abstract}
The article aims to discuss the standing for a private person to bring a penal action in crimes against the collective interest, such as environmental crimes. It's based on the hypothesis that the fundamental procedural guarantee must beat the service of the principle of exclusive protection of legal values. Thus, after analyzing the current legislation and addressing the controversy established in doctrine and jurisprudence on the subject, it is concluded that it is imperative to adopt interpretation which favors access to justice by expanding the list of plaintiffs, so that ensure the protection of the collective interests.

Keywords: criminal action, environmental crime, plaintiffs, collective interest, private person
\end{abstract}

\section{Introdução}

A atenção do presente artigo jurídico centra-se na ação penal privada subsidiária da pública; particularmente, na análise da legitimidade de agir quando a inércia ministerial se refere à propositura de denúncia em crimes vagos; o que se pode exemplificar com os crimes ambientais.

\footnotetext{
${ }^{1}$ Mestre e Doutora, PUC/SP; Professora Adjunta de Direito Penal da Faculdade de Direito da UFBA (Graduação e PPGD).

${ }^{2}$ Mestre e Doutoranda, PPGD/UFBA; Professora Assistente de Direito Penal da Faculdade de Direito, UFBA (Graduação); Advogada criminalista.
} 
O direito é um dos instrumentos necessários para regular as situações de risco e de dano que são criadas em prol do desenvolvimento econômico, científico ou tecnológico. E, para tanto, haverá de restringir a esfera de liberdade, de realização de certas atividades. $\mathrm{O}$ reconhecimento de novos direitos, como ao meio ambiente sadio, implica sempre alguma restrição àqueles já assegurados ao menos formalmente.

Dada a relevância do bem jurídico a ser protegido, o recurso, não apenas ao direito administrativo ou civil, mas também ao direito penal faz-se inevitável para a prevenção e repressão das lesões mais graves causadas ao meio ambiente. O grande desafio do direito penal contemporâneo é não poder deixar de assegurar as garantias e liberdades e individuais, mas, de outro lado, quando necessário, sancionar fatos que impliquem lesões que podem assumir proporções catastróficas em relação a bens considerados relevantes.

O meio ambiente foi reconhecido como bem jurídico autônomo, ao passo que deixou de se confundir com os demais valores tradicionalmente protegidos, como por exemplo a vida, a saúde e a propriedade, por possuir substantividade própria, por ser valioso em si mesmo, em razão de sua conservação e sua manutenção ser essencial ao ser humano e ao provimento de suas necessidades existenciais.

Essa mudança de enfoque, inspirada em movimentos sociais e que atendeu a exigências comunitárias, revela-se na Constituição Federal de 1988, quando dispõe, no artigo 225 , caput, que "todos têm direito ao meio ambiente ecologicamente equilibrado", e, no parágrafo $3^{\circ}$, determina a intervenção penal, além de medidas administrativas e da reparação dos danos, para as "condutas e atividades consideradas lesivas ao meio ambiente".

A Lei n. 9.605/98 tipifica condutas e comina sanções visando à proteção penal do meio ambiente. A lesão ao meio ambiente afeta a toda sociedade, assim, quando da ocorrência de um crime, o acesso à justiça para efetivação dessa tutela, caberá, em regra, ao Ministério Público, por meio do oferecimento da denúncia. Mas, diante da inércia do Ministério Público, a ação penal privada subsidiária da pública também pode ser instrumento prático de realização da tutela penal de bens da comunidade.

O problema é que apesar do assento constitucional da ação penal privada subsidiária da pública, como garantia fundamental, o Código de Processo Penal e o Código Penal não possuem regra específica sobre o tema quanto à legitimidade da propositura da referida ação nesses casos. 
Surgem, então, inadvertidamente, no ordenamento jurídico pátrio, erráticas interpretações doutrinárias que limitam, indevidamente, a aplicabilidade de tal garantia às infrações penais que possuem vítima determinada (LIMA, 2015, p. 254; FEITOSA, 2010, p. 289), bem como o próprio Supremo Tribunal Federal apresentou, recentemente, no julgamento da Petição 6071, conceito reducionista de sujeito passivo do delito, segundo o qual seria apenas "a pessoa ou entidade que sofre os efeitos diretos do delito" (BRASIL, 2016). Em tais linhas de intelecção, a indevida restrição à legitimidade para agir a um só tempo afronta a garantia constitucional do acesso à justiça, bem como deixa desprotegidos os bens jurídicos tutelados pela norma incriminadora.

O presente trabalho, portanto, parte da hipótese de que a garantia processual deve estar a serviço da desejável proteção penal determinada no âmbito material pelo princípio da exclusiva proteção de bem jurídico; não sendo possível interpretações restritivas no tocante à legitimidade de agir da ação penal privada subsidiária da pública, se a Constituição não fez limitações.

Assim, tem-se como questão central do trabalho o seguinte: diante da inércia do Ministério Público, a quem assiste a legitimidade para persecução criminal formal na queixa substitutiva em crimes que afetam os bens jurídicos coletivos, a exemplo dos crimes ambientais?

O tema é atualíssimo e sua investigação justifica-se pela relevância prática, utilidade social, importância intelectual e dado o alheamento científico da doutrina pátria ao problema. Articula, perfeitamente, com a linha de pesquisa "Acesso à Justiça" e, especialmente, se notabiliza pela compreensão do mútuo relacionamento entre o texto constitucional, o Código de Processo Penal e as leis penais. Sob a lente da Constituição Federal de 1988, não é possível enxergar o processo penal senão como um veículo de consolidação do regime democrático e, por óbvio, como chave mestra que dá acesso à justiça, garantindo-a.

Para enfrentar o problema, foi realizada pesquisa teórica, por meio da análise de livros, teses e periódicos nacionais e estrangeiros; e pesquisa documental, por meio do levantamento e análise da legislação nacional, bem como de decisões do Supremo Tribunal Federal.

O trabalho, então, foi construído a partir da realização de pesquisa descritiva e exploratória, visando esclarecer a importância da proteção penal do meio ambiente, e, para 
tanto, a necessidade de se ampliar o acesso à justiça por meio da propositura da ação penal privada subsidiária da pública.

\section{0 meio ambiente enquanto bem jurídico-penal}

Com o desenvolvimento tecnológico e econômico, principalmente, em razão dos danos resultantes das intervenções de empresas e indivíduos sobre a natureza, surgiram demandas para preservação do meio ambiente, que então se tornou um bem valioso em si mesmo, merecedor de maior proteção jurídica, como propugna a Constituição (art. 225, $3^{\circ}$ ).

Assim, o meio ambiente deixou de se confundir com os demais valores tradicionalmente protegidos, como por exemplo a vida, a saúde e a propriedade, por possuir substantividade própria, por ser valioso em si mesmo (PRADO, 1992, p. 67-68; DOTTI, 1991).

O meio ambiente, portanto, é conteúdo de um direito fundamental que se caracteriza pelo reconhecimento de valores sociais respeitantes aos seres humanos como um todo, cuja lesão tem uma extensão transindividual, por isso denominados interesses difusos (ou coletivos em um sentido amplo).

Para a definição da sua proteção, verifica-se que na doutrina predomina a perspectiva antropocêntrica. Nesse sentido, Rodríguez-Arias considera o meio ambiente um bem jurídico digno de proteção "porque é útil para o homem, ou melhor, indispensável; isto é, [...] enquanto fundamento existencial do ser humano", ressaltando, todavia, que deve haver uma moderação - quando lembra Albin Eser - "o homem não deve considerar-se apenas como usurpador ou usuário da natureza, senão como parte e componente dela". Partindo desta observação, admite que "poderia falar-se inclusive de uma proteção do meio ambiente por si mesmo, mas sempre considerando-o como um conjunto de elementos interrelacionados entre os quais se encontra o próprio ser humano" (1992, p. 24).

É o que José Souto de Moura (1994, p. 17) chama de antropocentrismo relativo, ou seja, o meio ambiente é protegido em busca da qualidade de vida do homem. Contudo, não existirá qualidade de vida humana, se não houver preservação do meio ambiente. Nesse mesmo sentido é o pronunciamento de Rodríguez-Arias (1992, p. 35), ao advertir que se por um lado o meio ambiente não é um valor absoluto, por outro, não se pode 
sacrificar o meio ambiente "em prol de uma utópica qualidade de vida totalmente desligada da natureza".

Enquanto Joan J. Queralt (1995, p. 21) fala de uma "dupla frente” de proteção pelo ordenamento jurídico, também no aspecto penal: de um lado o meio ambiente, do outro a pessoa humana, individual ou coletivamente, enquanto algumas condutas possam afetar diretamente ao ser humano.

Ainda sob a ótica antropocêntrica, há dois caminhos para a tutela do meio ambiente enquanto bem jurídico-penal: de um lado, argumenta-se que a intervenção penal procede desde que a afetação do meio ambiente ponha em perigo concreto ou abstrato a vida ou saúde das pessoas, ou inclusive outros interesses vitais destas; de outro lado, amplia-se esta concepção, para exigir que, no mínimo, sejam afetadas as gerações futuras.

Em relação a esta questão, Silva Sánchez (1996, p. 158-159) critica aqueles que sustentam que a configuração dos tipos penais relacionados ao meio ambiente trata da proteção dos seres humanos como gênero, compreendendo inclusive as futuras gerações; e explica que essa tese, embora dominante, "carece de critérios materiais praticáveis para delimitar os riscos tipicamente relevantes e irrelevantes, em matéria de meio ambiente. Isto é, para fixar o mínimo (em termos materiais da magnitude da afetação ao meio ambiente que dá lugar à apreciação da tipicidade." Defende, então, que não se pode falar em tipicidade se for possível descartar na conduta a existência de perigo algum para as condições de vida das pessoas, ou se a conduta repercute apenas sobre as condições de vida de gerações futuras. Conclui, portanto, que não há autonomia do bem supraindividual, mas dependência deste aos bens individuais, sendo necessário que à conduta que põe em perigo grave (concreto ou abstrato) o meio ambiente, esteja conectada uma perigosidade para a vida e saúde das pessoas $^{3}$.

Diante de tais posicionamentos, é preferível seguir considerando que, ao elevar a bem jurídico digno de tutela penal o meio ambiente, ou os elementos que o compõem, o alcance da

\footnotetext{
3 O referido autor atenta para o fato de que não pretende, com tal posicionamento, "converter os delitos contra o meio ambiente em meros delitos contra a vida e a saúde das pessoas. Mas sim, em contrapartida, por um lado, neutralizar a tendência a provocar a intervenção de um Direito Penal tão pronto como se afetam certo ecossistema em termos que superam os padrões administrativos estabelecidos, mesmo que possa excluir-se por completo uma repercussão no comportamento concreto em termos prejudiciais para a vida dos homens vivos. Por outro lado, e sobretudo, pretenderia excluir do âmbito do Direito penal aqueles casos em que só a soma de uma série de condutas pode provocar tal afetação prejudicial das condições de vida da pessoa." Assim como, afasta a idéia de afetar futuras gerações, pois desde a perspectiva atual, não pode constituir senão uma presunção, o que desbordaria os limites da intervenção jurídico-penal. (SILVA SÁNCHEZ, 1996, p. 159)
} 
lesão sofrida pelo ser humano, mediata ou imediatamente, será sempre relevante em tal apreciação. Portanto, em grau maior ou menor, predomina uma perspectiva antropocêntrica.

Em quaisquer das concepções adotadas, em caso de inércia ministerial no tocante à propositura de denúncia em crimes que afrontam tal bem jurídico, deve-se compreender que a proteção reclamada pelo Direito Penal deve corresponder a interpretações que garantam o acesso à justiça por parte dos sujeitos passivos do crime, com uma leitura ampla do rol de legitimados para propositura da ação penal privada subsidiária da pública.

A defesa de tal posição deve ser precedida de breves noções conceituais quanto à referida garantia processual fundamental.

\section{Breves notas sobre a ação penal privada subsidiária da pública}

No Brasil, existem três tipos de ação penal privada. A ação penal privada propriamente dita ou ação penal exclusivamente privada é aquela cujo exercício compete à vítima ou a quem legalmente a represente e está prevista no artigo 100 do Código Penal: " $\$ 2^{\circ}$ - A ação de iniciativa privada é promovida mediante queixa do ofendido ou de quem tenha qualidade para representá-lo."

A ação penal privada personalíssima é aquela cujo exercício cabe exclusivamente à vítima. No ordenamento jurídico pátrio, a aludida ação tem a sua aplicabilidade restrita ao crime de induzimento a erro essencial e ocultação de impedimento ao casamento, previsto no artigo 236 do Código Penal. Não há possibilidade de intervenção do representante legal nem sucessão por morte.

Há, ainda, a ação penal privada subsidiária da pública ou supletiva, que será objeto de referência específica neste artigo. A também denominada ação supletiva mereceu assento expresso no artigo $5^{\circ}$, inciso LIX, da Constituição da República Federativa do Brasil de 1988: "será admitida ação privada nos crimes de ação pública, se esta não for intentada no prazo legal". Trata-se de garantia constitucional fundamental, não podendo, portanto, ser suprimida do ordenamento pátrio nem por emenda constitucional por se tratar de cláusula pétrea.

\subsection{Hipótese de cabimento e características da ação penal supletiva}


A ação penal privada subsidiária da pública pode ser ajuizada nos casos de crimes de ação penal pública, se o Ministério Público não oferecer a denúncia, no prazo de lei. Surge a faculdade de o particular ajuizar a ação, no prazo de seis meses, iniciados a partir do término do prazo que o Parquet possui para atuar - em regra, cinco dias, se o investigado estiver preso, e quinze dias, no caso de se encontrar em liberdade (art.46, CPP).

Apesar da raríssima incidência prática, trata-se de espécie de controle particular da atividade ministerial ${ }^{4}$, de imperiosa necessidade, para garantir o efetivo acesso à justiça em casos em que a desídia ministerial causa embaraço à tutela dos bens jurídicos protegidos pela tipificação criminal; bem como em caso de eventual prática de crime de prevaricação pelo membro do Ministério Público.

Embora o ofendido esteja legitimado para iniciativa da propositura da ação penal essencialmente, tem-se uma ação de natureza pública ${ }^{5}$ submetida aos princípios da obrigatoriedade, da indisponibilidade, da intranscendência e da indivisibilidade; não havendo que se falar na incidência dos institutos afetos a ação penal privada, tais como renúncia, perdão e perempção. Como rememora Eugênio Pacelli (2017, p. 171), a ação subsidiária desloca para o ofendido unicamente "a iniciativa supletiva do exercício da ação penal".

Demais disso, na forma do artigo 564, inciso III, “d”, do Código de Processo Penal, a intervenção do Ministério Público é obrigatória. Após o ajuizamento da queixa crime substitutiva, o Parquet poderá aditá-la, repudiá-la, oferecer denúncia substitutiva, intervir em todos os termos do processo, fornecer elementos de prova, interpor recurso e, a todo tempo, no caso de negligência do querelante, retomar a ação como parte principal, na forma do art. 29 do CPP.

\section{A ação penal supletiva no caso de crimes ambientais}

\footnotetext{
${ }^{4}$ Embora o artigo 801 do CPP contemple, formalmente, a possibilidade de os órgãos do Ministério Público serem responsabilizados pelo retardamento da propositura da ação penal, ao perderem tantos dias de vencimentos quantos forem os excedidos; bem refira que na contagem do tempo de serviço, para o efeito de promoção e aposentadoria, a perda será do dobro dos dias excedidos (art. 801, parágrafo único, CPP ); tal disciplina não é válida à luz do direito à irredutibilidade dos subsídios do MP, previsto no art. 128, "c" da CF/88. Demais disso, as regras atinentes à promoção estão previstas na Lei Orgânica. Assim é que, na prática, faz-se necessário tal controle particular da atuação ministerial.

${ }^{5}$ Nesse sentido Eugênio Pacelli (2017, p. 171) ensina que se trata de "verdadeira e originária ação pública, em que será observada a regra da indisponibilidade, como consequência do princípio da obrigatoriedade. Ao ofendido, nesses casos, reserva-se apenas a iniciativa da propositura da ação”.
} 
Faz-se necessário discutir, então, sobre a legitimidade para a deflagração da ação penal subsidiária da pública no caso de crimes vagos, como no caso dos crimes ambientais.

Para Claus Roxin (2014, p. 57), o Direito Penal deve garantir como ultima ratio a convivência livre e pacífica dos cidadãos. Refere o penalista que um meio ambiente não destruído tem importância essencial para as possibilidades de desenvolvimento do indivíduo na sociedade; não havendo contradição dos bens jurídicos da comunidade com o conceito pessoal de bem jurídico.

A garantia processual da ação supletiva deve estar a serviço da desejável proteção penal determinada no âmbito material pelo princípio da exclusiva proteção de bem jurídico. A ação penal privada supletiva pode ser o instrumento prático de realização da tutela penal de bens da comunidade quando há inércia ministerial.

Será discutido, então, a quem assiste a legitimidade para persecução criminal formal na queixa substitutiva em crimes que afetam diretamente os bens jurídicos coletivos, como é o caso dos crimes ambientais; ou, também, poder-se-ia, indagar em caso de crimes contra administração pública, os crimes contra a fé pública, os crimes eleitorais, os crimes financeiros ou os crimes previstos na Lei antidrogas, por exemplo.

\subsection{Posicionamento doutrinário}

Sucede que apesar do assento constitucional da matéria, nem o Código de Processo Penal, nem o Código Penal possuem regra específica sobre o tema quanto à legitimidade da propositura da referida ação nesses casos. Dessa forma, cumpre verificar como a literatura penal cuida dessa questão.

Para Renato Brasileiro de Lima (2015, p. 254), no silêncio da Constituição Federal e do Código de Processo Penal a respeito do assunto, só há ação penal privada subsidiária da pública se a infração possuir um ofendido determinado. A título exemplificativo, o autor cita os crimes de perigo, tais como o porte ilegal de arma de fogo e o tráfico de drogas.

Na doutrina pátria, na mesma linha de intelecção, Denilson Feitosa (2010, p. 289) compreende que se o crime não possuir vítima determinada não haverá uma pessoa física ou jurídica que possa oferecer a queixa crime subsidiária.

Entretanto, tal restrição doutrinária viola a Constituição Federal, e, também, não pode ser deduzida do sistema pátrio. Não se pode interpretar restritivamente uma garantia 
fundamental, se a Constituição Federal não estabeleceu os limites à sua aplicabilidade; ao revés, uma hermenêutica constitucional comprometida com a proteção dos bens jurídicos coletivos deve privilegiar a razão de ser da ação penal privada subsidiária da pública que é, precisamente, colmatar a lacuna deixada pela ausência de atuação ministerial, devolvendo, pois, à vítima o direito potestativo ao ajuizamento da ação já que esta tem direito à aplicação da lei penal.

Deve-se destacar, como faz Anastácio Nóbrega Tahim Júnior (2016), que "se tratando de ação pública em sua essência, pois, como qualquer uma outra, seu móvel não é um interesse particular da vítima, mas o interesse público que anima e justifica a própria repressão criminal”. Refere, ainda, acertadamente, em contraposição ao entendimento esposado pelos doutrinadores citados, o seguinte: “já que a possibilidade de abuso não é característica exclusiva de determinados delitos, igualmente, a providência engendrada não pode ser privilégio privativo dos crimes que tenham, como sujeito passivo, alguém individualmente considerado e determinado". (TAHIM JÚNIOR, 2016)

Essa orientação não colide com o monopólio do Parquet no tocante à privatividade da promoção da Ação Penal Pública, prevista no artigo 129, I da CF/88; precisamente, porque a norma constitucional que prevê a garantia da Ação Penal Privada subsidiária da pública tem status constitucional, estando, inclusive, topograficamente, situada no título II, no rol dos "Direitos e garantias fundamentais". Também, não fere o sistema acusatório pois, como já advertido pelo Supremo Tribunal Federal, "A lei dá ao Ministério Público, na sua condição de dominus litis, as primícias; se ele deixar de atuar no prazo de lei, desveste-se do privilégio legal e enseja que, em seu lugar, passe a atuar o ofendido." ${ }^{\circ}$ A iniciativa da vítima é meramente supletiva e os direitos de defesa serão todos garantidos.

Julio Fabbrini Mirabete (1994, p. 121) preleciona, a propósito, "que garantia constitucional não contempla qualquer restrição ao princípio, não podendo restringi-lo a lei ordinária", bem como rememora a ação penal privada subsidiária da pública tem aplicação em relação à legislação penal especial, a exemplo da Lei de Falências, do Código Eleitoral e do Código de Processo Penal Militar. No mesmo sentido entende Tourinho Filho (1997, p. 73).

\footnotetext{
6 Refere, ainda, o STF que "Se, após, o Ministério Público acordar da letargia e pedir o arquivamento da representação, o tempo não retroage em seu favor, para que ele possa fazer o que deixou de fazer tempestivamente, e não desloca o ofendido diligente que substituiu o Ministério Público indolente" (BRASIL, 1992)
} 
Deve-se, portanto, privilegiar as interpretações que favoreçam a ampliação do rol de legitimados para assegurar que a proteção oferecida pelo direito material não seja esvaziada, processualmente, pela ilegítima restrição doutrinariamente formulada ao seu emprego apenas em caso de vítimas determinadas; tampouco, se deve restringir exclusivamente ao cidadão a possibilidade de atuação em tais casos, como se verá adiante.

\subsection{Projetos de Lei n. 6404/2016 e n. 8.045/2010}

Tramita na Câmara dos Deputados Projeto de Lei n. 6404/2016, apresentado em 25.10.2016, que altera o Código Penal e o Código de Processo Penal, a fim de permitir que qualquer cidadão promova a ação penal privada nos casos em que o Ministério Público não ofereça a denúncia no prazo legal. (BRASIL. Câmara dos Deputados, 2017)

Segundo o Projeto de Lei n. 6404/2016, o artigo 100, do Código Penal, passa a vigorar com a seguinte redação: “Art. 100 - A ação penal é pública, salvo quando a lei expressamente a declara privativa do ofendido." " $\$ 3^{\circ}$ - A ação de iniciativa privada pode ser proposta por qualquer cidadão nos crimes de ação pública, se o Ministério Público não oferece denúncia no prazo legal."

Os artigos 29 e 30, do Código de Processo Penal, passariam a vigorar com a seguinte redação:

Art. 29. Será admitida ação privada, a ser proposta por qualquer cidadão, nos crimes de ação pública, se esta não for intentada no prazo legal, cabendo ao Ministério Público aditar a queixa, repudiá-la e oferecer denúncia substitutiva, intervir em todos os termos do processo, fornecer elementos de prova, interpor recurso e, a todo tempo, no caso de negligência do querelante, retomar a ação como parte principal.

De modo inovador, o Projeto de Lei n. 6404/2016 contempla no seu artigo $3^{\circ}$ a possibilidade de ajuizamento da ação supletiva nos casos em que o Ministério Público entenda não haver crime; devolvendo a responsabilidade ao Poder Judiciário, enquanto fiscal do princípio da obrigatoriedade, de decidir, fundamentadamente, sobre o prosseguimento ou não da ação. A proposta, seguramente, se aprovada, será um avanço no sentido de amparar os interesses da vítima e de promover a efetiva resposta a ações atentatórias aos bens jurídicos coletivos. Todavia, como se verá adiante, há ainda uma indevida restrição da legitimidade de agir apenas para o "cidadão", deixando de fora as organizações sociais, associações ou outras instituições públicas. 
Nesse sentido, o projeto é insuficiente pois restringe o oferecimento da denúncia ao cidadão e, portanto, traduz um déficit de legitimação para o seu exercício, não prestigiando o amplo acesso à justiça, enquanto valor constitucional relevante.

O Projeto de Lei n. 8.045/2010, por sua vez, refere-se à "vítima", sem especificar os legitimados para agir em caso de afronta a bem jurídico coletivo. Veja-se a redação:

Art. 48. Se o Ministério Público não intentar a ação penal no prazo previsto em lei, poderá a vítima, ou, no caso de sua menoridade civil ou incapacidade, o seu representante legal, no prazo de 6 (seis) meses, contado da data em que se esgotar o prazo do órgão ministerial, ingressar com ação penal subsidiária.

Assim é que, ainda que haja as referidas implementações de reforma legislativa, a matéria continuará carecendo de interpretação sistemática para integração da lacuna.

\subsection{Posicionamentos do Supremo Tribunal Federal}

A jurisprudência pátria consagrou-se no sentido de que a ação penal privada subsidiária da pública só é cabível em caso de inércia ministerial; não sendo possível o seu ajuizamento em caso de o Ministério Público se pronunciar pelo arquivamento ou promover retorno do inquérito policial para realização de diligências externas. Em caso de arquivamento, por decisão judicial, a pedido do Ministério Público, há antigo precedente paradigmático do Supremo Tribunal Federal (BRASIL, 2004), no julgamento do Inquérito 1939/BA, no sentido de que não cabe ação penal subsidiária. No caso de o Parquet ter requerido diligências externas, não se mantendo inerte, também, a queixa subsidiária não tem sido admitida.

Em decisão recentíssima, o Supremo Tribunal Federal (BRASIL, 2015), em sede de repercussão geral no recurso extraordinário com agravo ARE 859251/RG, decidiu que a ausência de movimentação externa ao Ministério Público por prazo superior ao legal faz surgir o direito potestativo à propositura da ação penal privada subsidiária pela vítima e sua família. A questão constitucional foi resolvida no sentido de que diligências internas ou outras considerações puramente afetas à instituição são irrelevantes e não obstam o ajuizamento da ação. Demais disso, reconheceu-se que o texto constitucional não exige a desídia ou culpa por parte do Ministério Público, mas, tão somente, o simples decurso do prazo. 
As teses veiculadas no ARE 859251 RG referem-se às seguintes questões constitucionais:

(i) o ajuizamento da ação penal privada pode ocorrer após o decurso do prazo legal, sem que seja oferecida denúncia, ou promovido o arquivamento, ou requisitadas diligências externas ao Ministério Público;

(ii) a conduta do Ministério Público posterior ao surgimento do direito de queixa não prejudica sua propositura. Assim, o oferecimento de denúncia, a promoção do arquivamento ou a requisição de diligências externas ao Ministério Público, posterior ao decurso do prazo legal para a propositura da ação penal, não afastam o direito de queixa. Nem mesmo a ciência da vítima ou da família quanto a tais diligências afasta esse direito, por não representar concordância com a falta de iniciativa da ação penal pública. (BRASIL, 2015)

Como, na espécie, se tratava de imputação de crime de homicídio culposo resultante de inobservância de regra técnica de profissão ( $\operatorname{art} 121, \S \S 3^{\circ}$ e $4^{\circ}, \mathrm{CP}$ ), não se problematiza a discussão central desse trabalho que é a questão da legitimidade de agir em crimes que afrontam bens jurídicos coletivos. Sucede que dentre as razões de decidir estabelece-se que a “invocação de circunstâncias não presentes na regra constitucional para afastar sua consequência viola de forma direta a Constituição". Tal ratio decidendi deve-se afigurar como diretriz interpretativa da matéria em análise sob o viés constitucional garantista (BRASIL, 2015).

Assentou-se no Supremo Tribunal Federal (BRASIL, 2015), ainda, que o direito da vítima e sua família à aplicação da lei penal foi elevado à condição de direito fundamental pela Constituição e que não se trata de interesse meramente personalista, isto é, apenas das partes; mas de todo o sistema jurídico em marcar os limites do instituto, razão pela qual se reconheceu a relevância jurídica da matéria e sua submissão ao controle da repercussão geral. Não se discutiu no julgado quem pode ser considerado vítima porque no caso os seus representantes legais eram, facilmente, identificados.

Outras duas decisões do Supremo Tribunal Federal merecem, particular, referência, para os fins estabelecidos neste artigo jurídico.

O Supremo Tribunal Federal (BRASIL, 2014) julgou nos autos dos embargos de declaração no Inquérito n. 3862 que os conselhos indigenistas não possuem legitimidade ativa em matéria penal e rejeitou a queixa-crime subsidiária de denúncia proposta pelo Conselho Aty Guassu Guarani Kaiowa e Conselho do Povo Terena em face dos Deputados Federais Luis Carlos Heinze e Alceu Moreira, imputando-lhes a prática dos crimes de crime de racismo 
e incitação à violência e ódio contra os povos indígenas (art. 20, caput, e $\S 2^{\circ}$ da Lei $n^{\circ}$ 7.716/89, na redação dada pela Lei $\mathrm{n}^{\circ}$ 9.459/97).

No bojo da decisão diz-se que a queixa-crime foi ajuizada por organizações nãogovernamentais e que tais entidades possuem legitimidade em tutela coletiva extrapenal nos termos do artigo $5^{\circ}$, V, da Lei 7.347/85 $5^{7}$. No caso específico, recusou-se o reconhecimento da legitimidade porque não havia nos autos documento formalizando a representação dos ofendidos.

Como obiter dictum, aduziu-se que ainda que se cogitasse legitimidade extraordinária em virtude da lesão transindividual à honra da comunidade indígena, seria a FUNAI a competente para propor a ação na forma do art. 1, parágrafo único, da Lei no 5.371/67. Reconhece-se, ainda, que "Excepcionalmente, há situações em que, por expressa previsão legal, o legitimado para o oferecimento da queixa-crime subsidiária pode ser pessoa física ou entes não ligados diretamente ao ofendido" (BRASIL, 2014).

Em decisão monocrática da lavra do Ministro Luís Roberto Barroso, datada de 14 de abril de 2016, alusiva à petição tombada sob o n. 6071, argumentou-se que no Brasil não há uma "ação penal popular, hipótese em que qualquer do povo poderia dar início a persecução penal de crimes de ação penal pública [...] não havendo um interesse difuso de todo e qualquer particular na condenação". A petição tombada sob o n. 6071 se referia à instauração de ação penal privada subsidiária da pública proposta por um advogado contra Chefe do Poder Executivo pela suposta prática dos crimes tipificados nos artigos 147, duas vezes; 299, 312, entre outros crimes contra a administração pública, todos previstos no Código Penal; “art. 350 do Código Eleitoral; arts. $1^{\circ}, \S 1^{\circ}$, I e II, $\S 4^{\circ}$ da Lei $n^{\circ} 9.613 / 1998$ e arts. $1^{\circ}, \S \S 1^{\circ}, 2^{\circ}$ e $\S 3^{\circ}$ da Lei $n^{\circ} 12.850 / 2013$ ” (BRASIL, 2016).

Alguns dos crimes imputados referiam-se, em tese, a violações a bens jurídicos coletivos e, portanto, com interesse público na persecução. Sucede que o Ministro Relator Luís Roberto Barroso apresentou um conceito reducionista de "vítima" ou "ofendido", ao afirmar que se trata de particular que sofre diretamente os efeitos do delito. Referiu que "sujeito passivo do delito é a pessoa ou entidade que sofre os efeitos diretos do delito".

\footnotetext{
${ }^{7} \mathrm{O}$ referido artigo $5^{\circ}$ dispõe que "Têm legitimidade para propor a ação principal e a ação cautelar: [...] V - a associação que, concomitantemente: a) esteja constituída há pelo menos 1 (um) ano nos termos da lei civil; b) inclua, entre suas finalidades institucionais, a proteção ao patrimônio público e social, ao meio ambiente, ao consumidor, à ordem econômica, à livre concorrência, aos direitos de grupos raciais, étnicos ou religiosos ou ao patrimônio artístico, estético, histórico, turístico e paisagístico".
} 
Argumentou o julgador que "a invocada condição de cidadão do Querelante, por si só, não satisfaz o interesse processual, porquanto não direta e pessoalmente afetado pelas condutas imputadas à Querelada". Arrematou para concluir que "a sociedade, e portanto o conjunto de cidadãos, sempre será sujeito passivo do delito, mas o será de forma indireta" (BRASIL, 2017).

No julgamento do agravo regimental na petição n. 6071, reafirmou-se que a "legitimidade para o ajuizamento de ação penal privada subsidiária da pública pertence a quem sofra, diretamente, as conseqüências do delito, e não à toda coletividade.” Isto porque, segundo a Primeira Turma do STF não existia qualquer crime dentre os que foram imputados à ex-presidente que possuísse como sujeito passivo o agravante; justamente, porque se optou por um conceito restritivo de vítima.

\section{Legitimação para agir na ação penal privada subsidiária da pública e a necessidade de interpretação que favoreça a proteção de bens jurídicos e a garantia de acesso à justiça}

Possui legitimidade para agir o titular de uma situação jurídica material (TOURINHO FILHO, 2002, p. 176). Trata-se de condição genérica para o exercício da ação penal (pública ou privada), cuja ausência importa, nos termos do art. 395 do Código de Processo Penal, na rejeição da denúncia ou queixa.

O artigo 100, parágrafo $2^{\circ}$ do Código Penal dispõe que: “A ação de iniciativa privada é promovida mediante queixa do ofendido ou de quem tenha qualidade para representá-lo" $\mathrm{O}$ Código de Processo Penal, por sua vez, estabelece no seu art. 30 que: "Ao ofendido ou a quem tenha qualidade para representá-lo caberá intentar a ação privada”

No Brasil, os Códigos referidos não conceituaram quem é o "ofendido" ou "vítima", nem quem tem qualidade para representá-la; razão pela qual se trata de atividade hermenêutica, sempre comprometida com os valores sistêmicos.

O nó górdio da matéria é, precisamente, identificar quem são os legitimados quando a afronta disser respeito a bens jurídicos coletivos, como nos casos dos crimes ambientais.

O que se observa na jurisprudência pátria são atribuições de significados inapropriados aos conceitos de "vítima", "ofendido", "sujeito passivo"; numa espécie de manipulação discursiva inidônea para chegar, erraticamente, à conclusão da ilegitimidade para agir de determinados membros do grupo afetados pelos crimes ou organizações sociais e restringir, 
ilegitimamente, a tutela dos bens jurídicos protegido pela norma incriminadora, bem como ocasionar indevida limitação ao acesso à justiça, garantia prevista no art. $5^{\circ}$, inciso XXXV da Constituição Federal, que assegura que "a lei não excluirá da apreciação do Poder Judiciário lesão ou ameaça a direito". Não apenas a lei, mas a atividade hermenêutica não pode fazer a referida exclusão.

No caso da Ação penal privada subsidiária da pública, o legitimado para agir é "ofendido" ou "vítima"; que é o titular do bem jurídico protegido pela norma penal ou seja, o sujeito passivo do crime.

Luiz Flávio Gomes (1982, p. 131-132), no âmbito do processo penal, como medida assecuratória do interesse difuso, defendia que tanto o particular não prejudicado, quanto as associações e os órgãos públicos especializados poderiam promover a ação penal privada subsidiária da pública quando o Ministério Público não ajuizasse a ação no prazo determinado.

Como refere Anastácio Nóbrega Tahim Júnior (2016), "nos chamados crimes vagos, muito embora o bem penalmente protegido pertença, num primeiro momento, à coletividade, pertence, também, aos que, individualmente, a integra, até porque é aquela coletividade destituída de personalidade jurídica”.

A Declaração dos Princípios Básicos de Justiça Relativos às Vítimas da Criminalidade e de Abuso do Poder adotada pela Assembléia Geral das Nações Unidas na sua Resolução n. 40/34, de 29 de novembro de 1995, embora seja um soft law, afigura-se como diretriz interpretativa de política criminal legislativa internacional e deve ser considerada como topoi de argumentação para justificar a interpretação que favoreça a ampliação do rol de legitimados para propositura da ação supletiva.

A Resolução n. 40/34, de 29 de novembro de 1995, solicita aos Estados membros que se empenhem em "estabelecer e reforçar os meios necessários à investigação, à prossecução e à condenação dos culpados prática de crimes;” e recomenda aos Estados, também, "proporcionar meios de recurso acessíveis às vítimas, quando as vias de recurso existentes a nível nacional possam revelar-se insuficientes". 8

\footnotetext{
${ }^{8}$ NAÇÕES UNIDAS. Assembleia Geral. Resolução n. 40/34, de 29 de novembro de 1985. Declaração dos princípios básicos de Justiça Relativos às vítimas da criminalidade e de abuso do poder. Disponível em:http://www2.camara.leg.br/atividade-legislativa/comissoes/comissoes-permanentes/cdhm/comite brasileirode-direitos-humanos-e-politica-externa/AplicDecPricBasJustVitCriAbuPod.html. Acesso: 20 mai 2017.
} 
A declaração dos princípios básicos de Justiça Relativos às vítimas da criminalidade e de abuso do poder, no item "a", 1 do seu anexo, apresenta o conceito de vítima:

Entendem-se por 'vítimas' as pessoas que, individual ou coletivamente tenham sofrido um prejuízo, nomeadamente um atentado à sua integridade física e um sofrimento de ordem moral, uma perda material, ou um grave atentado aos seus direitos fundamentais, como consequência de atos ou de omissões violadores das leis vigor num Estado membro, incluindo as que proíbem o abuso de poder.

A questão central do bem jurídico ambiental é a indeterminação dos sujeitos que o titularizam. Todos se beneficiam com a sua proteção e gozo e, da mesma forma, são indistintamente prejudicados com sua violação. Esposando tal entendimento, Álvaro Luiz Valery Mirra (2007, p. 115) diz que o objeto desse direito ou interesse é indivisível, haja vista que "sua proteção beneficia a todos os indivíduos da sociedade, da mesma forma que sua lesão prejudica igualmente todos os seus titulares indistintamente".

Do quanto ficou dito, Márcio Flávio Mafra Leal (1998, p. 106) resume ao tratar do interesse difuso: "Praticamente toda a definição legal refere-se ao problema da titularidade do direito que, sinteticamente, quer dizer que o direito não tem titularidade determinável no plano individual e sua violação atinge indiscriminadamente toda a comunidade". Dessa forma, quando houver referência a tal qualificativo, deve-se ter em linha de consideração uma espécie de interesse que não pode se referir com exclusividade a um sujeito individual com faculdade de disposição sobre ele. ${ }^{9}$

No caso em apreço, o bem jurídico é titularizado, inicialmente, pela coletividade e, também, pelos que individualmente a integram, já que a coletividade é destituída de personalidade jurídica (TAHIM JÚNIOR, 2016).

Na mesma linha de intelecção, considerando-se que a violação a tais bens jurídicos atinge, indiscriminadamente, toda a comunidade, é que se defende que se deve admitir a legitimidade de agir nos crimes ambientais para ação supletiva: às associações, às organizações não governamentais, aos órgãos públicos especializados que incluem em suas finalidades institucionais a proteção ao meio ambiente ${ }^{10}$, bem como o membro do grupo

\footnotetext{
9 A propósito, merece alusão: DE LA MATA BARRANCO, Norberto. Protección penal del ambiente y accesoriedad administrativa: tratamiento penal de comportamientos perjudiciales para el ambiente amparados en uma autorización administrativa ilícita. Barcelona: Cedes, 1996.

${ }^{10}$ No caso dos crimes vagos que se referem às relações de consumo, a solução está no artigo 80 da Lei n. 8 . 078/1990: "No processo penal atinente aos crimes previstos neste código, bem como a outros crimes e contravenções que envolvam relações de consumo, poderão intervir, como assistentes do Ministério Público, os legitimados indicados no art. 82, inciso III e IV, aos quais também é facultado propor ação penal subsidiária, se a denúncia não for oferecida no prazo legal”.
} 
determinado no caso concreto que tenha sido efetivamente lesado com a violação do bem jurídico, demonstrando, processualmente, o seu interesse de agir.

Franklyn Roger Alves Silva (2017, p. 397) defende, ainda, que a leitura conjugada do artigo 80 do CDC com o art. 4, incisos II e VII, da Lei complementar n. 80/90, permitem concluir que a Defensoria Pública possui legitimidade para atuar, no caso em comento, nas persecuções criminais que digam respeito "a crimes atentatórios a interesses difusos e coletivos penais".

A crítica que lhe foi dirigida por Patrick Cacicedo (2017, p. 414-415) no sentido de que a defesa de tal legitimidade subsidiária para crimes com bens jurídicos coletivos viabilizaria que a instituição se tornasse "mais um agente impulsionador do poder punitivo do Estado, com a consequente reprodução de desigualdades sociais e da violação da vida e dignidades humanas", carece de base empírica idônea e tal petição de princípio não justifica a sua exclusão do rol de possíveis legitimados para ação supletiva, cuja missão, também, é a de promover valores constitucionais e não pode ser vista num prisma monofocal.

\section{Considerações finais}

A garantia processual fundamental da ação penal privada subsidiária da pública deve estar a serviço da tutela penal determinada pelo princípio da exclusiva proteção de bem jurídico, inclusive nos crimes vagos, como é o caso dos crimes ambientais.

À luz dos valores constitucionais pátrios, não são válidas as interpretações que restringem a sua aplicabilidade a crimes com vítima determinada; sendo certo que se deve privilegiar a razão de ser da ação penal privada subsidiária da pública que é, justamente, colmatar a lacuna deixada pela ausência de atuação ministerial, garantindo-se o acesso à justiça ao sujeito passivo da ação criminal e a efetividade do seu direito à aplicação da lei penal.

No tocante aos crimes contra a propriedade imaterial, o artigo 530, h, do CPP, dispõe que: "Art. 530-H. As associações de titulares de direitos de autor e os que lhes são conexos poderão, em seu próprio nome, funcionar como assistente da acusação nos crimes previstos no art. 184 do Código Penal, quando praticado em detrimento de qualquer de seus associados." Malgrado não se trate especificamente de legitimação para ação penal supletiva, permite-se que uma associação participe do processo penal como assistente de acusação. 
Desta forma, defende-se que as interpretações quanto aos legitimados a agir nas ações supletivas seja ampla para garantir que a tutela penal de bem jurídico valioso não seja, processualmente, esvaziada, pela ilegítima restrição aos casos de vítimas determinadas.

No tocante aos crimes ambientais, deve-se admitir como dedução lícita do sistema pátrio que estão legitimados a agir, em caso de inércia ministerial, as associações, as organizações não governamentais e os órgãos públicos especializados que incluem em suas finalidades institucionais a proteção ao meio ambiente; bem como o membro do grupo determinado no caso concreto que tenha sido efetivamente lesado com a violação do bem jurídico, demonstrando, processualmente, o seu interesse de agir.

\section{Referências}

BRASIL. Câmara dos Deputados. Projeto de Lei n. 6404/2016. Altera os Decretos-Lei no 2.848, de 7 de dezembro de 1940 - Código Penal, e no 3.689, de 3 de outubro de 1941 Código de Processo Penal, a fim de permitir que qualquer cidadão promova a ação penal privada nos casos em que o Ministério Público não ofereça denúncia no prazo legal. Disponível em: http://www.camara.gov.br/proposicoesWeb/prop_mostrarintegra?codteor= 1501924\&filename=PL+6404/2016. Acesso em:11 mai 2017.

BRASIL. Senado Federal. Projeto de Lei n. 8045/2010. Que trata do Código de Processo Penal. Disponível em: http://www.camara.leg.br/internet/comissoes/comissoes-especiais/ cpp.pdf. Acesso em 19 de mai. de 2017.

BRASIL. Supremo Tribunal Federal. RHC 68430, Relator(a): Min. PAULO BROSSARD, Segunda Turma, julgado em 24/03/1992, DJ 08-05-1992 PP-06266 EMENT VOL-01660-02 PP-00274 RTJ VOL-00140-03 PP-00834.

BRASIL. Supremo Tribunal Federal. HC 74276, Relator(a): Min. CELSO DE MELLO, Primeira Turma, julgado em 03/09/1996, DJe-037 DIVULG 23-02-2011 PUBLIC 24-02-2011 EMENT VOL-02470-01 PP-00081

BRASIL. Supremo Tribunal Federal. Inq 1939, Relator(a): Min. SEPÚLVEDA PERTENCE, Tribunal Pleno, julgado em 03/03/2004, DJ 02-04-2004 PP-00011 EMENT VOL-02146-02 PP-00258 RTJ VOL 00192-02 PP-0054

BRASIL. Supremo Tribunal Federal. Inq 3862 ED, Relator(a): Min. ROBERTO BARROSO, Primeira Turma, julgado em 18/11/2014, ACÓRDÃO ELETRÔNICO DJe-244 DIVULG 1112-2014 PUBLIC 12-12-2014

BRASIL. Supremo Tribunal Federal. ARE 859251 RG, Relator(a): Min. GILMAR MENDES, julgado em 16/04/2015, PROCESSO ELETRÔNICO REPERCUSSÃO GERAL MÉRITO DJe-094 DIVULG 20-05-2015 PUBLIC 21-05-2015

BRASIL. Supremo Tribunal Federal. Pet 6071, Relator(a): Min. ROBERTO BARROSO, julgado em 14/04/2016, publicado em PROCESSO ELETRÔNICO DJe-074 DIVULG 18/04/2016 PUBLIC 19/04/2016.

BRASIL. Supremo Tribunal Federal. Pet 6071 AgR, Relator(a): Min. ROBERTO BARROSO, Primeira Turma, julgado em 13/09/2016, PROCESSO ELETRÔNICO DJe-063 DIVULG 29-03-2017 PUBLIC 30-03-2017. 


\section{A LEGITIMIDADE PARA PROPOSITURA DA AÇÃO PENAL PRIVADA SUBSIDIÁRIA DA PÚBLICA EM CRIMES QUE AFETAM BENS JURÍDICOS COLETIVOS. O EXEMPLO REPRESENTATIVO DOS CRIMES}

AMBIENTAIS

CACICEDO, Patrick. Crítica científica a "legitimação não tradicional da ação penal": Defensoria Pública e a tutela de direitos por meio do direito penal - uma recusa. Revista Brasileira de Direito Processual Penal. Porto Alegre, vol. 3, n. 1, p.407-416, jan./abr. 2017.

DE LA MATA BARRANCO, Norberto. Protección penal del ambiente y accesoriedad administrativa: tratamiento penal de comportamientos perjudiciales para el ambiente amparados en uma autorización administrativa ilícita. Barcelona: Cedes, 1996.

DOTTI, René Ariel. Meio ambiente e proteção penal. Fascículos de ciências penais. Porto Alegre: 4 (1): 9-29, jan./mar, 1991.

FEITOSA, Denilson. Direito Processual Penal: teoria, crítica e práxis. 7 ed. Niterói/RJ: Editora Impetus, 2010.

GIDI, Antônio. Rumo a um Código de Processo Civil Coletivo: a codificação das ações coletivas no Brasil. Rio de Janeiro: Editora Forense, 2008.

GOMES, Luiz Flávio. O Ministério Público e a tutela jurisdicional dos interesses difusos. Justitia. São Paulo, 44 (116), p.117-132, jan./mar.1982.

FEITOSA, Denilson. Direito Processual Penal: teoria, crítica e práxis. 7 ed. Niterói/RJ: Editora Impetus, 2010.

LEAL, Márcio Flávio Mafra. Ações coletivas: história, teoria e prática. Porto Alegre: Sérgio Antônio Fabris Editor, 1998, p. 106.

LIMA, Renato Brasileiro de. Manual de Processo Penal. 3 ed. rev. ampl. Atual. Salvador/BA: Editora JusPODIVM, 2015.

MIRABETE. Julio Fabbrini. Processo Penal, 3 Ed. , São Paulo: Atlas, 1994. p. 121

MIRRA, Álvaro Luiz Valery. Associações civis e a defesa dos interesses difusos em juízo: do direito vigente ao direito projetado. In: GRINOVER, Ada Pellegrini; MENDES, Aluisio Gonçalves de Castro; WATANABE, Kazuo (Coord.). Direito processual coletivo e o anteprojeto do Código Brasileiro de Processos Coletivos. São Paulo: RT, 2007. p. 115.

MOURA, José Souto de. O crime de poluição: a propósito do art. $279^{\circ}$ do Projeto de Reforma do Código Penal. In: Textos. Lisboa: Centro de Estudos Judiciários, Ambiente, 1994. p. 11-33.

NAÇÕES UNIDAS. Assembleia Geral. Resolução n. 40/34, de 29 de novembro de 1985. Declaração dos princípios básicos de Justiça Relativos às vítimas da criminalidade e de abuso do poder. Disponível em: http://www2.camara.leg.br/atividade-legislativa/comissoes/ comissoes-permanentes/cdhm/comitebrasileiro-de-direitos-humanos-e-politicaexterna/

AplicDecPricBasJustVitCriAbuPod.html. Acesso: 20 mai 2017.

PACELLI, Eugênio. Curso de processo penal. 21 ed. rev. atual e ampl. São Paulo: Atlas: 2017.

PRADO, Luiz Regis. Direito penal ambiental: problemas fundamentais. São Paulo: Revista dos Tribunais, 1992.

QUERALT, Joan J. El delito ecologico en España: situacion actual y perspectivas de reforma. Revista Brasileira de Ciências Criminais. São Paulo: ano 3, n. 9, p. 19-32, jan./mar., 1995.

RODRÍGUEZ-ARIAS, Antonio Mateos. Derecho penal y protección del medio ambiente. Madrid: Colex, 1992.

ROXIN, Claus. Novos estudos de Direito Penal. Tradução de Luis Greco. Org. Alaor Leite. São Paulo: Marcial Pons, 2014.

SILVA, Franklyn R. A. Legitimação não tradicional da Ação Penal: a tutela de bens jurídicos por outras instituições públicas. Revista Brasileira de Direito Processual Penal, Porto Alegre, vol. 3, n. 1, p. 367-404, jan./abr. 2017. 
SILVA SÁNCHEZ, Jesús-Maria. Consideraciones teóricas generales sobre La reforma de los delitos contra el medio ambiente. In: Colecció Estudis juridics, n. 2. La reforma de La justicia penal. Estudios en homenaje al Prof. Klaus Tiedemann. Castelló, Universitat Jaume I, 1996, p. 151-181.

TAHIM JÚNIOR, Anastácio Nóbrega. Ação Penal privada subsidiária nos crimes vagos. Disponível em: http://www.prgo.mpf.gov.br/doutrina/ANASTACIO50.htm. Acesso em: 10 mai. 2016

TOURINHO FILHO, Fernando da Costa. Código de Processo Penal Comentado. Volume 1, 2 ed., São Paulo: Saraiva, 1997. 